\title{
Differences in School-readiness among Pre-school Children in Rural and Urban areas of Kisumu County, Kenya
}

\author{
Catherine Vuhya Mbagaya \\ Maseno University, Kenya \\ P.O. Box 333-40105, Maseno, Kenya \\ Tel: 25-473-879-0881_E-mail: cmbagaya@maseno.ac.ke
}

Received: Dec. 12, 2020

Accepted: Jan. 15, $2021 \quad$ Published: February 1, 2021

doi:10.5296/jse.v11i1.18058 URL: https://doi.org/10.5296/jse.v11i1.18058

\begin{abstract}
This study compared primary school preparedness of urban and rural preschool children in Kisumu county, Kenya. Children were assessed on their level of learning and development in the following domains: pre-academic skills (pre-literacy and pre-mathematics, executive function, and socioemotional cognition. The sample consisted of 390 preschool children who had completed their curriculum and were transitioning to Grade One. Children were assessed using an adapted and validated form of the Measurement of Development and Early Learning (MODEL) global item set. We hypothesized that urban children would score higher on all domains of learning and development than rural children. Results showed that indeed urban children were more prepared for primary school than were rural children in all the domains of learning examined in this study. In order to achieve Sustainable Development Goal 4 on equitable quality education that ensures life-long learning for all, county and national government should invest in early childhood development and education (ECDE) in both rural and urban so that all boys and girls can be ready for primary education and improve future outcomes for all children.
\end{abstract}

Keywords: School preparedness, Early Childhood Development and Education 


\section{Introduction}

There has been a global shift towards investing in early childhood education. Many countries have increased these investments in order to promote equitable quality education for pre-school children. Increased investment is based on the realization that early childhood development and learning has a profound impact on learning throughout the school years (Hanushek \& Woessmann, 2008, 2012). In fact, it is predictor of future academic performance and economic success. Sustainable Development Goal 4 (SDG 4) is targeted towards ensuring inclusive and equitable quality education and promoting life-long learning opportunities for all. This goal is based on the principle that education is an inalienable human right which is indispensable in the achievement of sustainable development and good quality of life for the people. SDG 4.2 targets that by 2030, all boys and girls should have access to quality early childhood development, care and pre-primary education so that they are ready for primary education ((SDGs; United Nations, 2015). This highlights the need to define and measure competencies at the start of school, as a means of tracking progress towards SDG 4.2 using globally comparable instruments. The results of these measure should then inform national policy (Raikes, Yoshikawa, Britto, \& Iruka, 2017).

Despite the proven lifelong benefits of pre-primary education, half of the pre-primary school-age children in the world today, about 175 million children, are not enrolled in pre-primary education during these vital years. Data shows that in high-income countries, 83 per cent of children are enrolled in pre-primary education compared to only 22 per cent from low-income countries. Of the 31 countries with the lowest pre-primary enrolment rates, 29 are low- or lower-middle-income countries (UNICEF 2019). These variations enhance inequalities and lead to a missed opportunity in investing the children's lives. Despite deliberate efforts by governments to make quality pre-primary education universal, the expansion of early childhood education has been slow and uneven in most countries (UNICEF, 2019). There are wide variations in progress among regions, and across and within countries. These disparities affect millions of the world's youngest children. This therefore means that even within countries there may be profound differences in the quality of pre-primary education and subsequently, differences in preparedness for primary school.

Kenya has achieved relatively high ECDE enrollment over time with only modest government financial support. Net enrolment in pre-primary education increased from 33 percent in 2005 to 72 percent in 2014. Kenya continues to have one of the highest enrollment rates in Sub-Saharan Africa (Devercelli \& Sayre, 2016). According to Serem-Esinapwaka (2016) the devolving of ECDE functions to the 47 county governments in 2013 following the promulgation of the new constitution was a step in the right direction. It was expected that with devolution, county governments would allocate more resources to ECDE and develop model ECDE centers. This resulted in the enrolment of over 3 million children in the 40,219 ECDE centers across the country in 2014 from about 2.3 million in 2010 (Serem-Esinapwaka, 2016). As a result of the rapid increase in enrolment, ECDE is now in dire state because of minimum government funding, poorly equipped centers, poorly trained and remunerated teachers and a low income per capita of the citizens. Although the Constitution states that pre-primary education should be free, communities and parents have provided the majority of 
financing for ECDE services in recent decades. This financing is primarily in the form of fees that pay for teacher salaries because Kenya Government is minimally involved in the provision of the service (Ng'ang'a 2006). The motivation by communities and parents to take up financing of ECDE education is based on the fact that education is considered an important social ladder and a means to economic prosperity (Oburu \& Mbagaya, 2019). In view of the fact that Kenya is a resource limited country, with over $42 \%$ of its population living on less than 2 dollars per day (UNICEF, 2017), it is unlikely that many parents and communities would satisfactorily support these centers financially in order to meet the ECDE Service Standards and Guidelines (2006). The majority of Kenya's poor live in rural areas. In fact, 90 percent of Kenyans in the bottom 40 percent of the income distribution live in rural areas (World Bank 2016). Given the difference in income levels between rural and urban Kenya, rural ECDE centers are less resourced than urban ECDE centers. This is likely to lead to disparities in quality and primary school preparedness of learners who complete ECDE.

A recent study by Sitati et al, (2016) on compliance with the national ECDE Service Standards and Guidelines showed that both public and private ECDE centers had poor quality class-rooms, inadequate sanitation facilities, and unsafe playgrounds. These conditions may affect how children learn and their socioemotional well-being. An educational needs assessment for Kisumu city by Maoulidi (2008) noted that poorly remunerated teachers, poor physical facilities in ECDE centers and high poverty levels were hampering the achievement of the Millenium Development Goals on Education at the time. A later survey conducted in 2014, in 84 ECDE centers in Kisumu by the Kisumu County Education Network (K-CEN) and the County Government, showed that the situation in ECDE centers had not improved (K-CEN, 2014). In fact, the quality of ECDE services varies significantly across centers and can be very low. In addition, quality assurance mechanisms in ECDE is still weak (ELP, 2016). It is against this background that the present study sought to examine the preparedness of urban and rural pre-school children for primary school.

In line with Urie Bronfenbrenner's Bioecological model of development, contextual factors associated with where children live may have profound effects on their development and learning (Keenan \& Evans, 2009). The urban-rural continuum provides unique contexts for development. For example, differences in access to resources and childrearing norms and practices in urban and rural areas may be linked to disparities in early achievement (Miller \& Votruba-Drzal, 2013). Worldwide the incidence of extreme poverty is much more prominent in rural contexts than in urban contexts (Schroeder, 2010). Several aspects of scarceness which are prevalent in rural contexts may present high risk factors for early development and learning. A meta-analysis by Letourneau, Duffett-Leger, Levac, Watson, and Young-Morris (2013) found that socioeconomic status (SES) of the family had influences on child development. Lower SES status was associated with poorer outcomes in literacy, language and behavioral development of children. Hermida et al. (2019) investigated how poverty, rural or urban settings affect cognitive performance among 131 5-year-old Argentinian children. For the same level of socioeconomic status, children in rural settings performed consistently worse than children in urban settings on measures of executive functions and non-verbal intelligence. Similarly, in Peru, students attending rural schools demonstrated 
extremely poor learning outcomes and obtained results significantly below those of students in urban schools. This was attributed due to differences in school inputs and the learning and care environments that children were exposed to (Castro \& Rollstone, 2015). In Chile, there was a clear distinction in the development of early literacy skills of 240 children (four years old) from rural and urban disadvantaged families starting nursery school in Chile. The development of literacy skills was higher among urban children than they were among rural children (Förster \& Rojas-Barahona, 2014).

A study by Gan, Meng, and Xie (2016) showed that that school readiness differed between rural and urban children in China. Rural children scored lower on emotional and social skills, basic knowledge, and drawing and language competence subtests than did urban students. They however scored higher on sport skills, and understanding of both time and space. These disparities in school preparedness could be attributed to inequality in opportunities, processes and outcome in early childhood education (Hong, Liu, Ma \& Luo, 2015).

Although several studies have shown that rural pre-school children score lower learning outcomes, a few other studies have found a positive association between living in a rural context and academic achievement (Paxson and Schady, 2007; Miller et al., 2013). This therefore means that the influence of rural and urban contexts on learning and development is equivocal. In Africa, there is a dearth of knowledge on these differences.

\section{The present study}

The purpose of this study therefore was to examine differences in school preparedness between rural and urban pre-school children in Kisumu County, Kenya. This was done using an adapted and validated Measuring Early Learning Quality and Outcome (MELQO) direct assessment tool. MELQO's assessment was based on the Measure of Development and Early Learning (MODEL) global item set (UNESCO, et al., 2017). School preparedness was assessed based on four critical learning domains: pre-mathematics, pre -literacy, executive function and socioemotional cognition. It was hypothesized that pre-school children in urban areas would score higher than children in rural areas on all the of domains of learning assessed in this study. Thus they would be more prepared for primary school than rural children.

\section{METHODS}

\subsection{Procedure}

This was a cross-sectional study in which pre-school children were assessed on their preparedness for primary school using MELQO's direct assessment tool (UNESCO, et al., 2017). Experts (officers and teachers) in early childhood development and education examined the tools in a one-day workshop to determine validity of the instruments. Teachers and ECDE officials reviewed and adapted the MELQO items to ensure that they were aligned with the Kenya pre-school curriculum, the culture and local context in which the study was carried out. It was concluded that the MELQO items largely covered domains of the Kenyan curriculum and it compared very well with the Kenya School Readiness Assessment Tool (KSRAT). The KSRAT is published by the Ministry of Education with 
support from the United Nations Children's Fund (UNICEF). In order to improve validity of the assessments, decisions were made with regard to using letters that were commonly taught in early childhood education for the Letter Sound Identification task. To enable use of the MELQO direct assessments in rural areas, the tool was translated into dholuo language. This was done to ensure mapping of text so that the translation is not left to the individual assessors. The translation process involved both forward and back translation by independent linguists. Ten assessors who were graduates of Education were recruited to conduct the direct assessments. In order to have reliable assessments, the assessors participated in a three-day training workshop on how to carry out direct assessments and teacher interviews. A pilot study was carried out among 40 preschool children and the inter-rater reliability for the assessments in the pilot study was $>.85$. This study was approved for ethical issues by the Maseno University Ethics and Review Committee. Permission to carry out the study was also granted by the office of the County Director of Early Childhood Development and Education, Kisumu County. Having secured the necessary permissions, we proceeded with data collection in the selected ECDE centers.

\subsection{Participants}

Participants included 390 pre-school children (Male $n=198$ (50.8\%); Female $n=192$ (49.2) -who had just completed pre-primary level 2 (PP2) and were ready to transition to grade one and 20 ECDE teachers. Participants were drawn from both rural and urban areas in Kisumu county: Rural children were 202 (51.8\%) and Urban children were 188 (48.2\%). The children ranged in age between 48 months (4 years) to 123 months (10.3 years). For subsequent analysis however, those aged over 97 months were excluded. Participants were identified by first randomly selecting 19 schools ( 9 from urban areas and 10 from rural areas). From these, proportionate sampling method was used to select participants were from PP2. The number of those selected to participate from each ECDE classroom was based on the number of children enrolled in the classroom. Each child in the ECDE classroom therefore had an equal chance of being selected for the study.

\subsection{Measures}

The measurement of children's school readiness was assessed using the MELQO direct assessment tool. This tool was developed following concerted efforts by UNICEF, United Nations Education, Scientific and Cultural Organization (UNESCO), Brookings Institution and the World Bank. The instrument was initiated to promote feasible measurement of child development and learning and quality of learning environments within low- and middle-income countries. MELQO tools are comprised almost entirely of items taken from other instruments that have been tested within at least two low- or middle-income countries. This tool has been used in Tanzania to examine school readiness constructs (Raikes et al. 2019) and has shown evidence of cross-country validity in Tanzania, Mongolia, Lao PDR and Madagascar. For this study, the tools were subjected to an adaptation process to ensure alignment with cultural and government standards. In addition, background information was modified to capture family and child characteristics such as family size and parental occupation and sibling position. 
The tool measures four domains of development: executive function, socio-emotional development, early mathematical skill and early literacy skill. Below is a brief description of the constructs of the instrument (UNESCO, UNICEF, Brookings Institution and the World Bank, 2017):

(i) Executive function: This domain refers to the management of cognitive processes and includes regulation, approaches to learning and other skills that drive learning across a number of areas, as well as fine motor skills. The domain contains some of the strongest drivers of children's academic performance over time, including sustained attention, working memory and the ability to inhibit impulses. The reliability of this domain in the current study was $\alpha=.54$.

(ii) Social-emotional development: This domain refers to the skills that facilitate children's successful interactions with others, including peers, teachers and family members. These skills and competencies are crucial to children's inclusion and the development of healthy, positive relationships with peers and adults, and play an important role in helping children engage in school over time. The reliability for this domain was $\alpha=.73$

(iii) Pre-academic skills (literacy and mathematics): These two domains comprise the sub-domains of early mathematics and literacy skills. This area includes early skills like counting and letter/sound identification, which are considered fundamental to developing math and literacy skills later in life, and fine motor skills like being able to draw a person, which are also predictive of later development. The reliability for early mathematics (pre-mathematics) was $\alpha=.62$ while that for early literacy (pre-literacy) was $\alpha=.73$.

In order to measure preparedness for primary school, children were assessed using MELQO's direct assessment tool by trained enumerators at ECDE centres. Children were asked to respond to a series of questions and tasks measuring early literacy and early mathematics, executive function and social emotional development.

\section{Data Analysis and Results:}

Data derived from assessments was coded and organized for analysis using IBM SPSS Version 21. Scores for the various learning domains were created by calculating summary scores. Summary scores were derived by adding the scores on items in each task in a specific domain and dividing this with the number items. Subsequently, the scores on each task were again summed up and divided with the number of tasks in each domain. Means and standard deviations were thus used to determine the level of school preparedness in the domains of learning measured. It was preferred to use means as opposed to raw data because the use of means, puts tasks on more or less the same scale and allows simplified comparisons across various tasks and domains. Mean differences between children in rural and urban areas was determined using $t$-test. The statistical significance level was set at $\alpha=0.05$.

Table1 presents results on the assessment of preschool children on pre-literacy tasks. Results showed that children in urban areas scored higher $(\mathrm{M}=1.31, \mathrm{SD}=.27)$ in the pre-literacy domain than did children in rural areas $(\mathrm{M}=1.07, \mathrm{SD}=.35$ all pre-literacy $\mathrm{t}(380)=-7.29$, $\mathrm{p}<.01$. An examination of the various pre-literacy tasks showed that urban children 
consistently scored higher in expressive language, expressive vocabulary, letter identification, name writing and letter sound identification than did rural children (see Table 1). It is only in listening comprehension that there were no significant differences in scores between children in urban areas $(\mathrm{M}=.55, \mathrm{SD}=.32)$ and children in rural areas $(\mathrm{M}=.54, \mathrm{SD}=.37), \mathrm{t}(380)=$ $-.19, \quad \mathrm{p}=.85$.

Table 1. Rural - Urban Differences in Development and Early Learning: Pre-Literacy

\begin{tabular}{|c|c|c|c|c|c|c|c|c|}
\hline \multirow[t]{2}{*}{ Domain } & \multicolumn{2}{|l|}{$\begin{array}{l}\text { Total } \\
(\mathrm{N}=\mathbf{3 8 2})\end{array}$} & \multicolumn{2}{|l|}{$\begin{array}{l}\text { Urban } \\
(n=197)\end{array}$} & \multicolumn{2}{|l|}{$\begin{array}{l}\text { Rural } \\
(n=185)\end{array}$} & \multirow[t]{2}{*}{$t(d f)$} & \multirow[t]{2}{*}{ Sig } \\
\hline & M & $S D$ & $M$ & $S D$ & $M$ & $S D$ & & \\
\hline Pre-literacy & 1.19 & 1.63 & 1.31 & .27 & 1.07 & .35 & $-7.29(380)$ & .00 \\
\hline $\begin{array}{l}\text { Expressive } \\
\text { language }\end{array}$ & .78 & .29 & .89 & .28 & .68 & .25 & $-7.44(380)$ & .00 \\
\hline $\begin{array}{l}\text { Expressive } \\
\text { Vocabulary }\end{array}$ & 3.67 & 1.20 & .39 & 1.12 & .34 & 1.20 & $-4.48(380)$ & .00 \\
\hline Letter ID & .76 & .76 & .89 & .21 & .64 & .31 & $-9.11(380)$ & .00 \\
\hline Name Writing & .75 & .44 & .84 & .37 & .67 & .47 & $-3.84(380)$ & .00 \\
\hline $\begin{array}{l}\text { Listening } \\
\text { Comprehension }\end{array}$ & .54 & .35 & .55 & .32 & .54 & .37 & $-.19(380)$ & .85 \\
\hline Letter Sound ID & .61 & .46 & .73 & .43 & .51 & .46 & $-4.96(380)$ & .00 \\
\hline
\end{tabular}

Table 2 presents results on the assessment of preschool children on pre-mathematics tasks. Results showed that children in urban areas scored significantly higher $(\mathrm{M}=1.42, \mathrm{SD}=.25)$ in the pre-mathematics domain than did children in rural areas $(\mathrm{M}=1.32, \mathrm{SD}=.25) \mathrm{t}(380)=$ 4.30, $\mathrm{p}<.01$. An examination of the various pre-mathematics tasks showed that urban children scored higher $(\mathrm{M}=1.54, \mathrm{SD}=.32)$ in mental transformation tasks, than did rural children $(\mathrm{M}=1.41, \mathrm{SD}=, \mathrm{SD}=33), \mathrm{t}(380)=-3.90, \mathrm{p}<.01$. Scores in simple addition were also higher for urban children $(\mathrm{M}=.89, \mathrm{SD}=.39)$ than they were for rural children $(\mathrm{M}=.78$, 
$\mathrm{SD}=.52) \mathrm{t}(380)=-2.39, \mathrm{p}=.02$. Similarly, scores in number comparison were higher for urban children $(\mathrm{M}=.94, \mathrm{SD}=.62)$ than they were for rural children $(\mathrm{M}=.80, \mathrm{SD}=.31)$; $\mathrm{t}(380)=-2.73, \mathrm{p}=.01$. When compared to urban children $(\mathrm{M}=.97, \mathrm{SD}=.19)$, rural children scored significantly lower in number identification tasks $(\mathrm{M}=.80, \mathrm{SD}=.29) ; \mathrm{t}(380)=.70, \mathrm{p}$ $<.01$. In the same way, urban children scored higher $(\mathrm{M}=.93, \mathrm{SD}=.18)$ in producing sets as a pre-mathematical skill compared to rural children $(\mathrm{M}=.87, \mathrm{SD}=.40) ; \mathrm{t}(380)=-1.93, \mathrm{p}$ $=.05$. There were however no significant differences between urban and rural children in verbal counting and in spatial vocabulary (see Table 2).

Table 2. Rural - Urban Differences in Development and Early Learning: Pre-Mathematics

\begin{tabular}{|c|c|c|c|c|c|c|c|c|}
\hline \multirow[t]{2}{*}{ Domain } & \multicolumn{2}{|l|}{$\begin{array}{l}\text { Total } \\
(\mathrm{N}=\mathbf{3 8 2})\end{array}$} & \multicolumn{2}{|l|}{$\begin{array}{l}\text { Urban } \\
(n=197)\end{array}$} & \multicolumn{2}{|l|}{$\begin{array}{l}\text { Rural } \\
(n=185)\end{array}$} & \multirow[t]{2}{*}{$t(d f)$} & \multirow[t]{2}{*}{ Sig } \\
\hline & $M$ & $S D$ & $M$ & $S D$ & $M$ & $S D$ & & \\
\hline $\begin{array}{l}\text { Pre-mathemat } \\
\text { ics }\end{array}$ & 1.37 & .25 & 1.42 & .25 & 1.07 & .35 & $-4.30(380)$ & .00 \\
\hline
\end{tabular}

\begin{tabular}{lcccccccc}
\hline $\begin{array}{l}\text { Verbal } \\
\text { Counting }\end{array}$ & 3.80 & .62 & 3.83 & .58 & 3.76 & .66 & $-1.04(380)$ & .30 \\
\hline $\begin{array}{l}\text { Spatial } \\
\text { Vocabulary }\end{array}$ & .84 & .81 & .87 & .98 & .81 & .62 & $-.81(380)$ & .42 \\
\hline $\begin{array}{l}\text { Mental } \\
\text { Transformatio } \\
\text { n }\end{array}$ & 1.50 & .44 & 1.54 & .32 & 1.41 & .33 & $-3.90(380)$ & .00 \\
\hline $\begin{array}{l}\text { Simple } \\
\text { Addition }\end{array}$ & .83 & .46 & .89 & .39 & .78 & .52 & $-2.39(380)$ & .02 \\
\hline $\begin{array}{l}\text { Number } \\
\text { Comparison }\end{array}$ & .86 & .49 & .94 & .62 & .80 & .31 & $-2.73(380)$ & .01 \\
\hline $\begin{array}{l}\text { Number ID } \\
\text { Producing a }\end{array}$ & .88 & .26 & .97 & .19 & .80 & .29 & $-.70(380)$ & .00 \\
Set & .90 & .32 & .93 & .18 & .87 & .40 & $-1.93(380)$ & .05 \\
\hline
\end{tabular}

Table 3 presents data on pre-school children scores on executive function. Urban children scored significantly higher $(\mathrm{M}=1.06, \mathrm{SD}=.22)$ on executive function skills than did 


\section{NI Macrothink}

children in rural areas $(\mathrm{M}=1.95, \mathrm{SD}=.34) ; \mathrm{t}(380)=-3.70, \mathrm{p}<.01$. The scores for urban children were higher than those for rural children in the head-toes-knees-shoulder task (urban: $\mathrm{M}=1.76 \mathrm{SD}=.41 ;$ rural: $\mathrm{M}=1.51, \mathrm{SD}=.64 ; \mathrm{t}(380)=-4.53, \mathrm{p}<.01)$ and the pencil-tap task (urban: $\mathrm{M}=.91, \mathrm{SD}=.18$; rural: $\mathrm{M}=.87, \mathrm{SD}=.27 ; \mathrm{t}(380)=-2.00, \mathrm{p}=.05$ ). There were no significant differences among the two groups in the forward digit span and backward digit span task (See table 3).

With regard to socioemotional cognition, again urban children scored significantly higher (M $=.84, \mathrm{SD}=.26)$ than rural children $(\mathrm{M}=.73, \mathrm{SD}=.32), \mathrm{t}(380)=-3.37, \mathrm{p}<.01)$. Scores on empathy were higher among urban children $(\mathrm{M}=.82, \mathrm{SD}=.28)$ than they were among rural children $(\mathrm{M}=.76, \mathrm{SD}=.35) ; \mathrm{t}(380)=-1.99, \mathrm{p}=.05)$ This was also true on the task of understanding feelings (urban: $\mathrm{M}=.87, \mathrm{SD}=.29$; rural: $\mathrm{M}=.71, \mathrm{SD}=.36 ; \mathrm{t}(380)=-4.48$, $\mathrm{p}<.01)$ (see Table 4).

Table 3. Rural - Urban Differences in Development and Early Learning: Executive Function

\begin{tabular}{|c|c|c|c|c|c|c|c|c|}
\hline Domain & $\begin{array}{l}\text { Total } \\
(\mathrm{N}=\mathbf{3 8 2})\end{array}$ & & $\begin{array}{l}\text { Urban } \\
(n=197)\end{array}$ & & $\begin{array}{l}\text { Rural } \\
(n=185)\end{array}$ & & $t(d f)$ & Sig \\
\hline & $M$ & $S D$ & $M$ & $S D$ & $M$ & $S D$ & & \\
\hline $\begin{array}{l}\text { Executive } \\
\text { Function }\end{array}$ & 1.0 & .30 & 1.06 & .22 & .95 & .34 & $-3.70(380)$ & .00 \\
\hline HTKS Task & 1.63 & .55 & 1.76 & .41 & 1.51 & .64 & $-4.53(380)$ & .00 \\
\hline $\begin{array}{l}\text { Forward Digit } \\
\text { Span }\end{array}$ & .89 & .45 & .93 & .35 & .85 & .53 & $-1.90(380)$ & .06 \\
\hline $\begin{array}{l}\text { Backward } \\
\text { Digit Span }\end{array}$ & .59 & .45 & .61 & .45 & .56 & .45 & $-1.19(380)$ & .24 \\
\hline Pencil task & .89 & .23 & .91 & .18 & .87 & .27 & $-2.00(380)$ & 05 \\
\hline
\end{tabular}


Table 4. Rural - Urban Differences in Development and Early Learning: Socioemotional Cognition

\begin{tabular}{|c|c|c|c|c|c|c|c|c|}
\hline \multirow[t]{2}{*}{ Domain } & \multirow{2}{*}{$\begin{array}{c}\text { Total } \\
(\mathrm{N}= \\
\text { 382) } \\
M\end{array}$} & & \multicolumn{2}{|c|}{$\begin{array}{l}\text { Urban } \\
(n=197)\end{array}$} & \multicolumn{2}{|c|}{$\begin{array}{l}\text { Rural } \\
(\mathrm{n}= \\
185)\end{array}$} & \multirow[t]{2}{*}{$t(d f)$} & \multirow[t]{2}{*}{ Sig } \\
\hline & & $S D$ & $M$ & $S D$ & $\mathbf{M}$ & $S D$ & & \\
\hline $\begin{array}{l}\text { Socioemotional } \\
\text { Cognition }\end{array}$ & .79 & .30 & .84 & .26 & .73 & .32 & $-3.37(380)$ & .00 \\
\hline Empathy/PT & .79 & .32 & .82 & .28 & .76 & .35 & $-1.99(380)$ & .05 \\
\hline $\begin{array}{l}\text { Understanding } \\
\text { Feelings }\end{array}$ & .79 & .30 & .87 & .29 & .71 & .36 & $-4.48(380)$ & .00 \\
\hline
\end{tabular}

\section{Discussion}

In this study, we hypothesized that urban preschool children will be more prepared for primary school than rural children. Indeed, urban children consistently scored higher than rural children in all domains examined in this study: pre-literacy, pre-mathematics, executive function and socioemotional cognition. Higher scores indicated that they were more prepared for primary school than their rural counterparts. These results are consistent with previous findings that have compared performance of rural and urban children in academic and cognitive tasks. For example, in Peru (Castro \& Rollstone, 2015), Chile (Förster M. \& Rojas-Barahona, 2014), China (Gan \& Meng, 2016) and Argentina (Hermida et al., 2019) urban pre-school children than consistently scored here on learning tasks than rural children.

A review of existing literature in Africa shows that there is a dearth of empirical studies which document rural-urban differences in early learning outcomes at preschool level. The present study therefore highlights these variances that indicate their level of preparedness for primary school. The differences observed between rural and urban children can be attributed to the fact that rural ECDE centers are more poorly resourced than those in urban areas. In fact, an observation of classroom conditions in schools that participated in this study showed that rural schools were in poorer physical condition than were urban schools. Although the county government provides limited funding to support ECDE, this is insufficient in meeting all requirements. The low income per capita of rural citizens (Serem-Esinapwaka, 2016) makes it difficult for them to support their community ECDE schools financially as would their urban counterparts. This is likely to lead to disparities in quality of learning outcomes and the level of primary school preparedness of learners who complete ECDE. Sitati et al. (2016) observed that poor conditions may affect how children learn and their socioemotional well-being. 
Besides school conditions, lower SES in rural families could account for poorer outcomes among rural children in the learning domains examined in this study. Several aspects of scarceness which are prevalent in rural contexts may present high risk factors for early development and learning. For example: lack of access to social services, public health, and resources could affect how pre-school children learn and their outcomes (Hermida, et. al., 2019). Subsequently, this affects their preparedness for primary school. In addition, poverty reduces access to preschool education. Poorer children may not be able to attend school on a regular basis due to the need for children to help support the family (Nampushi \& Welsh 2015) or even due to lack of food since the likelihood of not having food or enough money to buy it increases with decreasing household wealth (World Food Programme, 2016). Lack of education in rural Kenya is far worse in rural areas in Kenya than in urban areas. About half (48\%)of the household heads in rural areas have little or no education compared to just $18 \%$ of their urban counterparts (WFP, 2016). Fewer years of parental education is associated with significantly less familiar stimulation at home (Biedinger 2011; Hermida et al., 2019). This may lead to poorer outcomes at pre-primary level and less than optimal preparedness for primary school.

\section{Conclusions}

The current study has documented learning outcomes of pre-school children in rural and urban areas of Kisumu county, Kenya. The study has empirically demonstrated that rural children are less prepared for primary school than children in urban areas in pre-academic skills (pre-literacy and pre-mathematics), executive function and socioemotional cognition. This is in agreement with previous studies done in Peru (Castro \& Rollstone, 2015), Chile (Förster M. \& Rojas-Barahona, 2014), China (Gan \& Meng, 2016) and Argentina (Hermida et al., 2019). This concurrence implies that despite the sociocultural differences associated with various countries, urban children perform better than rural children in academic and cognitive tasks. In view of the fact that ECDE has implications for future learning and subsequent economic benefits, children in rural ECDEs are less likely than their urban counterparts to have future academic and economic success. County and national governments in Kenya must deliberately put in place measures that seek to improve learning quality and outcomes in rural areas so that all children regardless of their locale have a good chance of future academic and economic success.

\section{Limitations}

Despite the fact that the current study is among the few studies on the African continent that have documented important knowledge on preparedness of preschool learners for primary school, the study should be viewed in light of the following limitations. First, the study was carried in one county in Kenya hence the results cannot be generalized to the whole country. This is because of within-country differences in resources, childrearing practices and cultural norms that have the potential to influence learning outcomes. Second, the study did not address differentiated mechanisms that account for the rural-urban distinctions in school preparedness.

\section{Suggestions for further research}




\section{$\Lambda$ Macrothink}

Journal of Studies in Education

ISSN 2162-6952

2021, Vol. 11, No. 1

In light of the above limitations, future studies should focus on a national sample of pre-school learners for assessments so that inter-county, and inter-region comparisons can be made and firm conclusions drawn. In addition, future research should endeavor to address the differentiated mechanisms that account for the rural-urban variances in learning outcomes so that interventions to improve these outcomes are well targeted.

\section{Acknowledgement and Sponsoring Information}

This study was funded by Global Ties for Children, New York University. The author is grateful for the funds that enabled assessments of children and interviews with teachers in Kisumu County Kenya.

\section{References}

Biedinger, N. (2011). The Influence of Education and Home Environment on the Cognitive Outcomes of Preschool Children in Germany. Child Development Research. https://doi.org/10.1155/2011/916303

Bradley R.H., \& Corwyn R.F. (2002). Socioeconomic status and child development. Annual Review of Psychology, 53, 371-399. https://doi.org/10.1146/annurev.psych.53.100901.135233

Carla E. Förster M., \& Cristian A. Rojas-Barahona. (2014). Disadvantaged Preschool Children from Rural Areas: The importance of home practices and nursery attendance in the development of early literacy skills. Culture and Education, 26(3), 476-504. https://doi.org/10.1080/11356405.2014.973668

Castro, J.F., \& Rolleston, C. (2015). Explaining the Urban-Rural Gap in Cognitive Achievement in Peru: The Role of Early Childhood Environments and School Influences. Available at: https://www.younglives.org.uk/sites/www.younglives.org.uk/files/YL-WP139-Castro.pdf

Keenan, T., \& Evans, S. (2009). Introduction to child development. London: Sage.

Devercelli, A., \& Rebecca Sayre. (2016). Scaling up preschool in Kenya: Costs, constraints and opportunities. Available at http://documents1.worldbank.org/curated/en/762961482316633811/pdf/111215-BRI-ELPPol icyBriefKenya-PUBLIC.pdf

Gan, Y., Meng, L., \& Xie, J. (2016). Comparison of School Readiness Between Rural and Urban Chinese Preschool Children. Social Behavior and Personality: An International journal, 44(9), 1429-1442. https://doi.org/10.2224/sbp.2016.44.9.1429

Hermida MJ, Shalom DE, Segretin MS, Goldin AP, Abril MC, Lipina SJ., \& Sigman M. (2019). Risks for Child Cognitive Development in Rural Contexts. Frontiers in Psychology, 9: 2735. https://doi.org/10.3389/fpsyg.2018.02735

Hong, X., Liu, P., Ma, Q., \& Luo, X. (2015). The way to early childhood education equity policies to tackle the urban-rural disparities in China. International Journal of Child Care and Education Policy, 9(5). https://doi.org/10.1186/s40723-015-0008-9 
Kenya Demographic Health Survey. (2014). Kenya National Bureau of Standards. Nairobi.

Kisumu County Education Network (K-CEN) (2014) The Status of Basic Education in Kisumu County; Kisumu County Education Education County

Kombo, J., \& Gogo, J. G. (2004). The role of the church in the provision of early childhood education in Nairobi, Kenya. Nairobi: Daystar University Centre for Research, Publication and Consultancy.

Letourneau N.L., Duffett-Leger, L. Levac, L., Watson, B., \& Young-Morris, C. (2013). Socioeconomic Status and Child Development: A Meta-Analysis. Journal of Emotional and Behavioural Disorders, 21(3), 211-224. https://doi.org/10.1177/1063426611421007

Maoulidi, M. (2008). MCI Social Sector Working Paper Series No 01/2008: Education Needs Assessment For Kisumu City, Kenya. Available at http://mci.ei.columbia.edu

Miller P., Votruba-Drzal E. (2013). Early academic skills and childhood experiences across the urban-rural continuum. Early Child Research. Quarterly 28, 234-248. https://doi.org/10.1016/j.ecresq.2012.12.005

Nampushi J., \& Welsh. N., (2015) Access Issues in Kenyan Primary Education available at http://www.dropoutprevention.org/engage-backup/access-issues-in-kenyan-primary-educatio $\mathrm{n} /$

Ng'ang'a, L.W., (2009). Early childhood education programs in Kenya: Challenges and solutions. Early Years 29(3), 2009. https://doi.org/10.1080/09575140902984400

Polit, DF, (1982). Family Size and child development. Draper Fund Rep., 11, 19-22.

Republic of Kenya. (2006). Early Childhood Development Service Standards and Guidelines for Kenya. Nairobi: Government Press.

Republic of Kenya. (2014). County early childhood education bill, 2014. Kenya Gazzette supplement No. 108 (Senate Bill No.32) of 2014. Nairobi: Government Printers.

Riechi. R. O., Mbiti. D. M., \& Kisilu. B. (2006). Policy Gaps and Suggested Strategies of Enhancing Access to Early Childhood Development and Education in Kenya; Institute of Policy Analysis and Research Discussion. Discussion Paper No. 089/2006: Nairobi: IPAR.

Serem-Esinapwaka. (2016) Working together to spur early childhood development in Kenya available at https://www.unicef.org/kenya/reallives_18795.html

Sitati, E.M., Ndirangu, M., Kennedy, B., \& Rapongo, G.S. (2016). Implementation of early childhood development education service standard guidelines on physical facilities in public and private early childhood education centres Kakamega County, Kenya, Early Child Development and Care,186(11), 1765-1778. https://doi.org/10.1080/03004430.2015.1131159

UNICEF. (2016). GOK - UNICEF Kenya Country Programme 2014 - 2018. Available at https://www.unicef.org/kenya/overview.html 


\section{Macrothink}

Journal of Studies in Education

ISSN 2162-6952 2021, Vol. 11, No. 1

World Bank, (2016). Republic of Kenya Urbanization Review. Washington. The World Bank. Available at

http://documents1.worldbank.org/curated/en/639231468043512906/pdf/AUS8099-WP-P148 360-PUBLIC-KE-Urbanization-ACS.pdf

World Food Programme: Comprehensive Food Security and Vulnerability Analysis (CFSVA) Kenya 2016. Available

at

https://reliefweb.int/sites/reliefweb.int/files/resources/wfp285586_b_0.pdf 